\title{
Evaluation of the immune response following a short oral vaccination schedule with hepatitis $B$ antigen encapsulated into alginate-coated chitosan nanoparticles
}

\author{
Olga Borges ${ }^{a, *}$, Joana Tavares ${ }^{b}$, Adriano de Sousa ${ }^{a}$, Gerrit Borchard $^{c}$, \\ Hans E. Junginger ${ }^{d}$, Anabela Cordeiro-da-Silva ${ }^{b}$ \\ a Center for Pharmaceutical Studies, Laboratory of Pharmaceutical Technology, Faculty of Pharmacy, \\ University of Coimbra, Rua do Norte, 3000-295 Coimbra, Portugal \\ $\mathrm{b}$ Institute for Molecular and Cell Biology and Laboratory of Biochemistry, Faculty of Pharmacy, \\ University of Porto, 4050-047 Porto, Portugal \\ c School of Pharmacy Geneva/Lausanne, University of Geneva, 1211 Geneva 4, Switzerland \\ d Faculty of Pharmaceutical Sciences, Naresuan University, Phitsanulok 65 000, Thailand
}

\section{A R T I C L E I N F O}

\section{Article history:}

Received 21 March 2007

Received in revised form 9 July 2007

Accepted 6 August 2007

Published on line 15 August 2007

\section{Keywords:}

Oral vaccination

Hepatitis B surface antigen

CpG oligodeoxynucleotide

Alginate-coated chitosan

nanoparticles

Vaccines

\begin{abstract}
A B S T R A C T
The purpose of this work was to assess the ability of recombinant hepatitis B vaccine, encapsulated in alginate-coated chitosan nanoparticles, to induce local and systemic immune responses following oral vaccination. The antigen was administered either alone or in combination with the immunopotentiator, synthetic oligodeoxynucleotide containing immunostimulatory CPG motif (CPG ODN) as adjuvant, and associated or not with the alginate-coated chitosan nanoparticles. After two immunizations the group I (HBsAg associated with nanoparticles) and the group VI (HBsAg and CpG, both associated with nanoparticles) showed enhanced immune responses. Both groups showed significant higher values of the CD69 expression in CD4+ and CD8+ T-lymphocytes and lower values of this marker in B lymphocytes. Moreover, a strongest proliferative response of the splenocytes, ex vivo stimulated with concanavalin A, was observed in the same groups. Although with a presence of non-responder mice within the groups, only mice of the groups I and VI elicited the generation of anti-HBsAg antibodies detected in serum (IgG) and in the intestinal washings (sIgA). The results demonstrated that coated chitosan nanoparticles might have potential for being used as a deliver system for oral vaccination with the recombinant hepatitis B surface antigen.
\end{abstract}

(c) 2007 Elsevier B.V. All rights reserved.

\section{Introduction}

According to a report of the World Health Organization (WHO/UNICEF, 2005), the estimated number of deaths in the world in all age groups from diseases preventable by vaccines in 2002 was 2.1 million, 600,000 deaths being due to hepatitis
B. The global coverage of infants with three doses of hepatitis B vaccine in 2004 was $48 \%$, contrasting with $3 \%$ in 1992. In the last few years, the majority of industrialized countries have introduced hepatitis B vaccination campaigns. Therefore, the above statistics of deaths due hepatitis $B$ are representative predominantly for the less developing countries, where mass

\footnotetext{
* Corresponding author. Tel.: +351 239859927; fax: +351 239827126.

E-mail address: olga@ci.uc.pt (O. Borges).
} 
vaccination has not been implemented yet (18\% of the 192 WHO member states). Its implementation is highly dependent on the development of more stable and cheaper vaccines for which the intervention of specialised human resources for the administration would not be required.

Oral administration has been appointed as the only economically feasible approach to mass vaccination. Impressive logistical advantages of orally administered vaccines were exemplified by two national vaccination days in 1996, when 121 million Indian children were vaccinated against polio at 650,000 centres (Bloom and Widdus, 1998). However, it has been shown that is very difficult to obtain a protective immune response following oral vaccination, the live-attenuated polio vaccines are being one of the few exceptions (Holmgren and Czerkinsky, 2005). For this reason, only few vaccines currently approved for human use are being administered orally.

Unfortunately, a simple oral formulation is not easily achieved for the new generation of subunit vaccines, which hold the greatest promise for disease prevention in the 21st century (Thanavala et al., 2005). Several explanations have been appointed to justify the disappointing results found for oral administration of subunit vaccines, being almost exclusively biotechnological products. One of the most important reasons is related with the adverse environment of the gastrointestinal tract (GIT), rich in acids and enzymes, which are able to destroy the antigen. Equally important is the mechanism of oral tolerance, the vital physiological role for dietary antigens in preventing hypersensitivity reactions to food or to commensal bacteria (Mowat, 2003; Nagler-Anderson, 2001). This hyporesponsivity to antigens orally administered is not yet fully understood, but it is thought that the mucosal immune system has involved a variety of mechanisms to achieve and maintain tolerance against self-antigens and against the overabundance of environmental antigens present in the microflora and food. Among them, activation-induced cell death, anergy and especially the induction of regulatory $\mathrm{T}$ cells are frequently reported in the literature (Holmgren and Czerkinsky, 2005). In a recent study (Gotsman et al., 2000) the induction of oral tolerance to hepatitis B virus proteins was achieved by the administration of five low oral doses of hepatitis $\mathrm{B}$ virus proteins, followed by two inoculations with a commercial vaccine.

In the case of the development of an oral hepatitis $B$ vaccine, this mechanism has to be circumvented and the antigen must be protected from physical degradation and enzymatic digestion (Holmgren and Czerkinsky, 2005). For this purpose, several strategies have been described in literature. Those approaches include the encapsulation of immunogenic peptide representing residues $127-145$ of the immunodominant B-cell epitope of hepatitis B surface antigen (HBsAg) in poly(D,L-lactide co-glycolide) (Rajkannan et al., 2006). Another strategies are the encapsulation of the plasmid DNA encoding hepatitis B virus protein in poly(D,L-lactide-co-glycolic acid) (PLGA) (He et al., 2005) or in Salmonella typhimurium (Gao et al., 2003; Woo et al., 2001; Zheng et al., 2001, 2002) or the genetic modification of edible plants for the production and delivery of the hepatitis B vaccine, within, e.g., potato tubers (Kong et al., 2001; Thanavala et al., 2005), cherry tomatillo (Gao et al., 2003) and lettuce (Kapusta et al., 1999, 2001). A very recent clinical study (Thanavala et al., 2005) with previously vaccinated vol- unteers showed that the ingestion of doses of $100 \mathrm{~g}$ uncooked potato tubes $(8.5 \mu \mathrm{g} / \mathrm{g})$ induced the increase of the serum antiHBsAg titers in about $60 \%$ of the volunteers, who ate three doses of the potatoes. Approximately $40 \%$ of the volunteers were non-responders to the HBsAg, therefore the necessity of simultaneous finding a good mucosal adjuvant in order to elicit an increase of the number of responders was emphasised by the authors of this study (Thanavala et al., 2005).

So, with this in mind the present study has as a main purpose, the evaluation of the potential of a chitosan-based nanoparticulate delivery system as a mucosal adjuvant.

Chitosan, a copolymer of D-glucosamine and N-acetyl-Dglucosamine is a derivative of chitin, one of the polysaccharides most abundant in nature. In the last few years, the properties of this biodegradable biopolymer have been intensively investigated. In particular, its ability to stimulate cells from the immune system has been shown in several studies (Babensee and Paranjpe, 2005; Borges et al., 2007; Nishimura et al., 1987; Shibata et al., 1997). For instance, the presence of chitosan in a dendritic cell culture-induced the expression levels of the co-stimulatory molecules CD86, CD40 and HLADQ (Babensee and Paranjpe, 2005), indicative of dendritic cell maturation. Likewise, chitosan has also shown to be able to up-regulate, in some extent, a number of macrophage functions (Nishimura et al., 1987; Shibata et al., 1997).

The polymer has also been used in the nanoparticle formulation for loading and delivering different vaccines, like meningococcal C conjugate (Baudner et al., 2002), diphtheria (van der Lubben et al., 2003) and tetanus toxoid (Jaganathan et al., 2005; Vila et al., 2004) or used without any modification, suspending the bulk powder in a solution of the meningococcal C conjugate vaccine (Baudner et al., 2005) or using a soluble chitosan derivative with the influenza vaccine (Bacon et al., 2000; Read et al., 2005) or finally using chitosan to surfacemodified PLGA microspheres containing hepatitis $B$ vaccine for intranasal immunization (Jaganathan and Vyas, 2006).

In a previous study, we have formulated and characterised alginate-coated chitosan nanoparticles (Borges et al., 2005). They consist of a chitosan core (chitosan nanoparticles) to which the hepatitis B vaccine was adsorbed and in a second step, the sodium alginate. The alginate coating is afterwards cross-linked with calcium ions. This delivery system has the particular advantage of being constructed under very mild conditions, which is a great benefit for the encapsulation of proteins, peptides and antigens. Moreover, in a very recent publication (Borges et al., 2006) we have demonstrated that these coated nanoparticles were able to be taken up by rat Peyer's patches which is one of the essential features to internalise, deliver and target the intact antigen to specialised immune cells from the gut associated lymphoid tissue (GALT) (Neutra and Kozlowski, 2006). This property makes these new nanoparticles a promising delivery system especially for oral vaccination.

Therefore, in the present study the feasibility of using the recombinant surface hepatitis B protein (HBsAg) encapsulated into the above-mentioned alginate-coated chitosan nanoparticles for the induction of local and systemic immune responses after oral vaccination was evaluated. Moreover, to improve the immune response, synthetic oligodeoxynucleotides containing immunostimulatory CpG motifs (CpG 
ODN), were also associated to the formulations, entrapped or not in the nanoparticles. CpG ODN acts as a potent adjuvant and has shown in a number of studies to induce a Th1 type immune response, not only when administered parenterally (Osorio et al., 2003; Weeratna et al., 2001) but also after mucosal vaccination (McCluskie and Davis, 2000; McCluskie et al., 2000a,b). It has been shown in non-human primates, that the CpG ODNs improve the immunogenicity of the hepatitis $B$ vaccine (Klinman et al., 2004). Regarding human clinical experience with CPG ODNs, limited information concerning the outcome of these trials has been released. However there are some few examples already reported in literature (Carpentier et al., 2006; Cooper et al., 2004; Friedberg et al., 2005). One such example is a double-blind phase I/II study with CpG 7909, as adjuvant to Engerix-B designed to evaluate the safety of $\mathrm{CpG}$ 7909 in healthy adults (Cooper et al., 2004). According with the authors of the same study, the most frequently reported adverse events were injection site reactions, flu-like symptoms and headache. Additionally, as reviewed somewhere else (Klinman et al., 2004), no clinically relevant changes in hematocrit or white blood cell count among immunized volunteers, nor were there any changes in liver or renal function and none of the subjects exposed to CpG ODNs developed signs or symptoms of autoimmune disease.

Therefore CpG ODN has been regarded as a promising adjuvant for the hepatitis $B$ vaccine and in the present study the possible advantages for its encapsulation were in vivo evaluated.

\section{Materials and methods}

\subsection{Materials}

\subsubsection{Polymers}

Ultra pure chitosan was purchased from Primex BioChemicals AS (Avaldsnes, Norway). According to the provider's specifications, the degree of deacetylation is $95 \%$ (titration method) and the viscosity is $8 \mathrm{cP}$ (measured in $1 \%$ solutions in $1 \%$ acetic acid). A low molecular weight pharmaceutical grade sodium alginate (MANUCOL LB ${ }^{\circledR}$ ) was kindly donated by ISP Technologies Inc. (Surrey, UK). According to the provider's specifications, the typical values for the percentage of mannuronic and guluronic acid for Manucol LB are 61 and 39\%, respectively, with an estimated molecular weight of $18 \mathrm{kDa}$.

\subsubsection{Antigen, adjuvant and reagents}

The hepatitis B surface antigen (HBsAg) (subtype ADW2) was kindly offered by GSK Biologicals (Rixensart, Belgium). Class B, CpG ODN (1826) (5'-TCC ATG ACG TTC CTG ACG TT-3') was purchased from Coley Pharmaceutical Group (Ottawa, Canada).

Concanavalin A (Con A), phenylmethanesulfonyl fluoride (PMSF), avidin peroxidise conjugate and the BCIP/NBT-purple liquid substrate system for membrane were from Sigma Chemicals (St. Louis, USA). Certified fetal bovine serum (FBS) and L-glutamine $(200 \mathrm{mM})$ were from Gibco (Invitrogen Co., Paisley, Scotland, UK), $1 \mathrm{M}$ HEPES buffer (0.85\%, $\mathrm{NaCl})$, RPMI 1640 without L-glutamine and Pen-Strep (10,000 U penicillin/ml; 10,000 $\mu$ g streptomycin/ml) were from Biowhitaker (Cambrex Bio Science, Verviers, Belgium). [methyl- $\left.{ }^{3} \mathrm{H}\right]$ thymi- dine $(1.0 \mathrm{mCi} / \mathrm{ml})$ was obtained from Amersham Biosciences (UK), R-Phycoerythrin (PE)-conjugated hamster anti-mouse CD69, fluorescein isothiocyanate (FITC)-conjugated rat antimouse CD4 and FITC-conjugated rat anti-mouse CD8 were obtained from BD Biosciences (Madrid, Spain). The FITCconjugated goat anti-mouse IgM (anti- $\mu$ ), the anti-mouse IFN- $\gamma$ and biotin rat anti-mouse IFN- $\gamma$ was purchased from PharMingen (San Diego, CA, USA). The mouse IgA ELISA quantitation kit was obtained from Bethyl Laboratories (Montgomery, USA). All others reagents used were analytic grade. All solutions were prepared in ultrapure water.

\subsection{Methods}

\subsubsection{Preparation of the coated nanoparticles}

The preparation of the alginate-coated chitosan nanoparticles was performed according to the method previously described by Borges et al. (2005). In brief, chitosan was dissolved at a concentration of $0.25 \%(\mathrm{w} / \mathrm{v})$ in diluted acetic acid solution. The formation of the particles was achieved after the addition of $3.5 \mathrm{ml}$ of sodium sulfate solution $(10 \%, \mathrm{w} / \mathrm{v})$ to $200 \mathrm{ml}$ of the chitosan solution. The resulting suspension was centrifuged for $30 \mathrm{~min}$ at $3500 \mathrm{rpm}(2800 \times \mathrm{g})$ and the supernatant was discarded. The particles were re-suspended in Millipore water and centrifuged twice. Finally they were frozen in liquid nitrogen and freeze-dried overnight using a Labconco freeze dry system (Labconco Corporation, Kansas, USA). The dry powder was kept frozen until further use.

The loading of the nanoparticles with HBsAg or with CpG ODN was performed separately by incubating a solution of HBsAg or the solution of CpG with a suspension of chitosan particles at pH 7.4 (phosphate buffer) under mild agitation at room temperature during $120 \mathrm{~min}$. The resulting suspensions with the composition of $0.015 \%(\mathrm{w} / \mathrm{v}) \mathrm{HBsAg}$ and $0.5 \%(\mathrm{w} / \mathrm{v})$ nanoparticles and the second with $0.015 \%$ (w/v) CpG and $0.5 \%$ $(\mathrm{w} / \mathrm{v})$ nanoparticles were used in the subsequent coating step. Alginate-coated nanoparticles were obtained by mixing equal volumes of nanoparticles suspension and a buffer phosphate solution of sodium alginate ( $1 \%, \mathrm{w} / \mathrm{v})$ under magnetic stirring. The agitation was maintained for $20 \mathrm{~min}$. The suspension was then centrifuged for $10 \mathrm{~min}$ at $1600 \mathrm{rpm}$ and the supernatant was discarded. The particles were re-suspended in $0.524 \mathrm{mM}$ $\mathrm{CaCl}_{2}$ in $50 \mathrm{mM}$ HEPES buffer solution, kept under agitation for another $10 \mathrm{~min}$ and immediately administered to the mice.

\subsubsection{Evaluation of the loading efficacy of HBsAg and} CPG ODN in coated nanoparticles

The loading efficacy of the coated particles was calculated by an indirect way, quantifying the antigen that remained in solution as described before (Borges et al., 2006). After the coating with alginate, an aliquot of the particle suspension was centrifuged at 14,000 rpm for $15 \mathrm{~min}$ and the protein in supernatant was quantified by micro-BCA-protein assay (PIERCE, Rockford, USA) using a microplate reader with a $570 \mathrm{~nm}$ filter.

For the CpGODN the same procedure was followed and the oligodeoxynucleotides was quantified, measuring the OD of the supernatants at $260 \mathrm{~nm}$. To eliminate background interference, the supernatant of unloaded particles were treated the same way. The results refer to the nanoparticle batches used in the vaccination studies (four batches for each immunization). 
The loading efficacy (LE) and the loading capacity (LC) were calculated from the following equations:

$$
\begin{aligned}
\mathrm{LE}(\%)= & \frac{\text { total amount of HBsAg or CpG }- \text { free HBsAg or CpG }}{\text { total amount of HBsAg or CpG }} \\
& \times 100
\end{aligned}
$$

LC $\left(\frac{\mu \text { g of HBsAg or CpG }}{\text { mg chitosan nanoparticles dry weight }}\right)$

$$
=\frac{\text { total amount of } \mathrm{HBsAg} \text { or CpG }- \text { free HBsAg or CpG }}{\text { mg chitosan nanoparticles dry weight }}
$$

\subsubsection{Evaluation of the structural integrity of the vaccine}

The integrity of hepatitis B antigen was confirmed using SDSpolyacrylamide gel electrophoretic (SDS-PAGE) analysis of the hepatitis $B$ vaccine released overnight from the nanoparticles (7.4 pH buffer phosphate; $37^{\circ} \mathrm{C} ; 50 \mathrm{rpm}$ ). The samples were centrifuged at $14,000 \mathrm{rpm}$ in order to separate the released antigen from the particles and an aliquot was then solubilised with the loading buffer and treated $\left(5 \mathrm{~min}\right.$ at $\left.100^{\circ} \mathrm{C}\right)$. The SDS-PAGE was performed in accordance with standard protocols (Coligan, 2001) with 12\% resolving gel, cast and run in tris-glycine buffer at $25 \mathrm{~mA}$ and finally stained with silver nitrate.

The antigenicity of the entrapped hepatitis B vaccine was assessed by Western blotting using a mouse antiserum raised against the native antigen. The hepatitis $B$ vaccine samples were transferred from the unstained gel onto a nitrocellulose membrane, using semi-dry electroblotting system (115 mA; $1 \mathrm{~h}$ ) and the membrane was blocked overnight at $4{ }^{\circ} \mathrm{C}$ with PBS-T (containing $0.05 \%$ of Tween 20 and $5 \%$ of milk). After washing with PBS-T, the membrane was incubated for $2 \mathrm{~h}$ at room temperature with the positive anti-HBsAg IgG mouse antiserum, diluted 1:500 in PBS-T with $5 \%$ of low fat milk. After washing with PBS-T, the membrane was incubated with antimouse IgG conjugated to alkaline phosphatase, diluted 1:750. The ability of the mouse antiserum to recognize hepatitis $B$ vaccine released from the nanoparticles was demonstrated colorimetrically using $5 \mathrm{ml}$ of phosphatase buffer with $33 \mu \mathrm{l}$ NBT $(50 \mu \mathrm{g} / \mathrm{ml})$ and $16.7 \mu \mathrm{l}$ BCIP $(50 \mu \mathrm{g} / \mathrm{ml})$. The reaction was stopped by washing the membrane with water.

\subsubsection{Immunization studies}

2.2.4.1. Animals. Six-week-old female BALB/c AnNHsd mice were used (Harlan Iberica, Barcelona, Spain) with four or six mice per group. Animals were housed for acclimatization 1 week before the experiments at the animal resource facilities of the Faculty in accordance with institutional ethical guidelines. They had free access to food and water, with $12 \mathrm{~h}$ light/dark cycle. Two hours before the oral vaccination and overnight before the end of the experiment, the mice were starved allowing only free access to water.

\subsubsection{Treatment groups.}

- Group I: suspension of alginate-coated chitosan nanoparticles loaded with $10 \mu \mathrm{g}$ HBsAg;
- Group II: suspension of alginate-coated chitosan nanoparticles loaded with $10 \mu \mathrm{g}$ HBsAg plus $10 \mu \mathrm{g}$ of the adjuvant (CpG ODN) in solution;

- Group III: untreated-control;

- Group IV: solution with $10 \mu \mathrm{g}$ HBsAg;

- Group V: solution with $10 \mu \mathrm{g}$ HBsAg and $10 \mu \mathrm{g}$ CpG ODN;

- Group VI: suspension of the mixture of alginate-coated chitosan nanoparticles loaded with $10 \mu \mathrm{g}$ HBsAg and particles loaded with $10 \mu \mathrm{g}$ CpG ODN.

2.2.4.3. Immunization schedule. Each animal received immediately before immunization $100 \mu$ l of a $7.5 \%$ sodium bicarbonate solution in order to neutralise the acid environment of the stomach. The different formulations, corresponding to each treatment group (see Section 2.2.4.2) were administered orally with a gavage-feeding needle. The primary immunization was followed by one boost 3 weeks later with $150 \mu$ l volume containing $10 \mu \mathrm{g}$ of the vaccine. The animals were sacrificed 10 days post-boost and a collection of blood from the heart, vaginal secretions, small intestinal washes and the spleen was carried out for analysis as described in the following sections.

2.2.4.4. Collection of samples. Blood samples were taken from the orbital sinus before the boost and by cardiac puncture at the end of the experiment and the sera were prepared by centrifugation and stored at $-20^{\circ} \mathrm{C}$ until analysis.

Vaginal and gut washes were obtained by rinsing with $(75 \mu \mathrm{l}$ $3 \times$ ) $225 \mu \mathrm{l}$ and $600 \mu \mathrm{l}$ cold PBS (containing $0.1 \%$ sodium azide, $0.1 \%$ bovine serum albumin (BSA) and $1 \mathrm{mM}$ PMSF) through the vagina or the intestine, respectively. The extract was vortexed, allowed to stay at room temperature for $15 \mathrm{~min}$ and then centrifuged $\left(6000 \mathrm{rpm} / 15 \mathrm{~min} / 4^{\circ} \mathrm{C}\right)$. The clear supernatants were stored at $-80^{\circ} \mathrm{C}$ until analysis.

2.2.4.5. Enzyme-linked immunosorbent assays (ELISA) for HBsAg-specific immunoglobulins. Ninety-six-well flatbottomed microtiter plates (Nunc immunoplate maxisorb) were previously coated (incubated overnight at $4{ }^{\circ} \mathrm{C}$ ) with the recombinant HBsAg $(1 \mu \mathrm{g} /$ well) in coating buffer $(50 \mathrm{mM}$ sodium carbonate, $\mathrm{pH}$ 9.6). The plates were washed five times with PBS-T (PBS containing 0.05\% Tween-20) and blocked with $3 \%$ BSA in PBS-T $(200 \mu \mathrm{l} /$ well $)$ during $1 \mathrm{~h}$ at $37^{\circ} \mathrm{C}$. The plates were then washed five times with PBS-T and the serial dilutions of each serum $(100 \mu \mathrm{l} /$ well $)$ from the individual mice were tested in triplicate, starting from a dilution 1:100 in PBS-T. The serum was incubated during $2 \mathrm{~h}$ at $37^{\circ} \mathrm{C}$ and after washing the plates with $\mathrm{PBS}-\mathrm{T}$, the plates were incubated for additional $30 \mathrm{~min}$ at $37^{\circ} \mathrm{C}$ with peroxidaselabeled goat anti-mouse immunoglobulin $\mathrm{G}$ and isotypes (anti-IgG1, anti-IgG2a, anti-IgG2b and anti-IgG3). The bound antibodies were revealed adding $100 \mu \mathrm{l} /$ well of $0.5 \mathrm{mg} / \mathrm{ml}$ of O-phenylenediamine dihydrochloride (OPD) (Sigma, Spain) in $10 \mathrm{ml}$ of citrate buffer with $10 \mu \mathrm{l}$ of $\mathrm{H}_{2} \mathrm{O}_{2}$. The reaction was stopped after $10 \mathrm{~min}$ with $50 \mu \mathrm{l}$ of $3 \mathrm{M} \mathrm{HCl}$ to each well. The absorbance was read out at $492 \mathrm{~nm}$ in an automatic ELISA reader (Easy Reader 400, SLT-LABINSTRUMENTS). Elisa titers were expressed as $\mathrm{mIU} / \mathrm{ml}$ and $1 \mathrm{mIU}$ is the OD mean of the pre-immune serum plus two times the standard deviation. 
The measurement of IgA was carried out using a mouse IgA ELISA quantification kit (Bethyl Laboratories, Montgomery, Texas, USA) as described by the manufacturer. In order to make a correct evaluation of the sIgA in the gut and vaginal extracts, total sIgA and the specific anti-HBs sIgA were determined in the extracts. The results are presented as the anti-HBsAg IgA/total IgA. By this way differences between samples related with the extraction process or stability of the sIgA were minimized.

The IgA standard was diluted to appropriate concentrations in PBS with 1\% BSA to create a calibration curve. The gut washes were diluted in PBS-T with $1 \%$ BSA and added to the plates in series of twofold dilutions. The concentrations of the total and specific IgA were determined from the calibration curve generated for each set of samples using a four-parameter logistic curve-fit generated by SigmaPlot software (version 8.0, SPSS Inc.).

2.2.4.6. Preparation of spleen cell suspensions. The mice were euthanized by cervical dislocation and their spleens were aseptically removed. Individual spleen cell suspensions were prepared in a Petri dish using curved needles and washed twice with RPMI 1640. The final suspension was adjusted to a final concentration of $1 \times 10^{7}$ cells $/ \mathrm{ml}$ in complete RPMI 1640 medium (supplemented with $10 \%$ (v/v) fetal bovine serum (FBS), 1\% (v/v) glutamine, 1\% (v/v) Pen-Strep and 2\% (v/v) $1 \mathrm{M}$ HEPES buffer).

\subsubsection{Cell population of the spleen. The cells} $\left(0.025 \times 10^{7}\right.$ cells $)$ were washed twice with cold PBSsupplemented with $2 \%$ FBS and then incubated in the dark for $30 \mathrm{~min}$ at $4{ }^{\circ} \mathrm{C}$ with saturated concentrations of FITC-conjugated rat anti-mouse CD4 or FITC-conjugated rat anti-mouse CD8 or FITC-conjugated goat anti-mouse IGM (anti- $\mu$ ). After incubation, cells were washed three times with PBS-2\% FBS and then re-suspended in $500 \mu$ l PBS-2\% FBS. To exclude dead cells, $2.5 \mu \mathrm{l}$ propidium iodide $(50 \mu \mathrm{g} / \mathrm{ml})$ were added just before data acquisition. At least 10,000 events were analysed by flow cytometric acquisition, performed in a fluorescent activated cell sorter (FACS Calibur) (BD, Biosciences, Madrid, Spain). Data were analysed by CellQuest software (BD, Biosciences, Madrid, Spain).

2.2.4.8. Splenocyte cell culture in the presence of the mitogens. Using sterile 96 -well flat-bottomed tissue culture plates, $25 \mu \mathrm{l}$ of splenocyte suspension $\left(1 \times 10^{7} \mathrm{cells} / \mathrm{ml}\right)$ from each mouse was plated in triplicate along with $25 \mu$ l of a complete RPMI solution of the mitogen (con A $(50 \mu \mathrm{g} / \mathrm{ml})$, CpG ODN $(50 \mu \mathrm{g} / \mathrm{ml})$ plus HBsAg $(25 \mu \mathrm{g} / \mathrm{ml})$ and HBsAg $(25 \mu \mathrm{g} / \mathrm{ml})$ alone). A fourth group of experiments were incubated with $25 \mu \mathrm{l}$ of a complete RPMI solution without any mitogen (negative control). Finally the volume of all the wells was completed to $200 \mu \mathrm{l}$ with complete RPMI and incubated at $37^{\circ} \mathrm{C}$ with $95 \%$ relative humidity and in the presence of $5 \% \mathrm{CO}_{2}$.

2.2.4.9. Cytokine production by splenocytes. Spleen cell suspensions were plated with the mitogens (see Section 2.2.4.8) and incubated in a humidified $5 \% \mathrm{CO}_{2}$ incubator for $24 \mathrm{~h}$ (IL-2) and $86 \mathrm{~h}$ (INF- $\gamma)$ at $37^{\circ} \mathrm{C}$. The plates were centrifuged and the supernatants stored at $-80^{\circ} \mathrm{C}$ until analysis.
IL-2 and IFN- $\gamma$ cytokines produced by splenocytes were determined by ELISA, following a technique described elsewhere (Cordeiro-da-Silva et al., 2004).

2.2.4.10. Evaluation of the CD69 expression on lymphocytes. After $20 \mathrm{~h}$ of incubation in the presence of different mitogens (see Section 2.2.4.8), cells were washed and re-suspended in cold phosphate buffered saline (PBS) supplemented with $2 \%$ FBS (PBS-2\% FBS), resulting in a concentration of $0.5 \times 10^{6}$ cells/well. The cells were then incubated in the dark for $30 \mathrm{~min}$ at $4{ }^{\circ} \mathrm{C}$ with saturated concentrations of PEconjugated hamster anti-mouse CD69 and FITC-conjugated rat anti-mouse CD4 or FITC-conjugated rat anti-mouse CD8 or FITC-conjugated goat anti-mouse IGM (anti- $\mu$ ). After incubation, cells were washed three times with PBS-2\% FBS and then re-suspended in $500 \mu \mathrm{l}$ of PBS-2\% FBS. To exclude dead cells, $2.5 \mu \mathrm{l}$ propidium iodide $(50 \mu \mathrm{g} / \mathrm{ml})$ was added just before data acquisition. The flow cytometry determinations were done according to the description given above (see Section 2.2.4.7).

2.2.4.11. Lymphoproliferation assay. Splenocytes were obtained and cultured together with the mitogens in a flat-bottomed 96 -well plate as described before (see Section 2.2.4.8). The cells were cultured for $96 \mathrm{~h}$ at $37^{\circ} \mathrm{C}$ and on the last $8 \mathrm{~h}$ of incubation; each well was pulsed with $1 \mu \mathrm{Ci}$ of [methyl $-{ }^{3} \mathrm{H}$ ] thymidine. 96 well plates with the cells were stored at $-20^{\circ} \mathrm{C}$ until further analysis. The cells were later thawed and harvested onto a fiberglass filter (filter mats, molecular devices, Skatron, Lier, Norway) using a semiautomatic cell harvester (Scatron Instruments, USA) and DNA thymidine incorporation was counted by standard liquid scintillation techniques with a Beckman LS 6500 scintillation counter (Beckman Coulter Inc., Fullerton, USA). Thymidine incorporation was expressed as counts per minute (cpm).

\subsection{Statistical analysis}

Data were presented as the mean \pm S.E.M. for at least three experiments and statistical significance was assessed using one-way ANOVA followed by Dunnett's post-test using the GraphPad Prism 4 software. Differences were considered significant when $p<0.05$.

\section{Results \\ 3.1. Characterization of the alginate-coated nanoparticles}

In a recent publication of our group (Borges et al., 2005), the development of alginate-coated chitosan nanoparticles and the characterization of this new delivery system were reported. Briefly, before coating with sodium alginate, the chitosan nanoparticles have a mean diameter of $643 \mathrm{~nm}$ (dynamic light scattering technique) and are positively charged $(+37 \mathrm{mV})$. Scanning electron microscopy (SEM) images of uncoated particles also revealed the presence of small nanoparticles (around $100 \mathrm{~nm}$ ) and demonstrated that the majority of the coated particles were in a range between 300 and $600 \mathrm{~nm}$ (Fig. 1). The presence of the alginate coating 

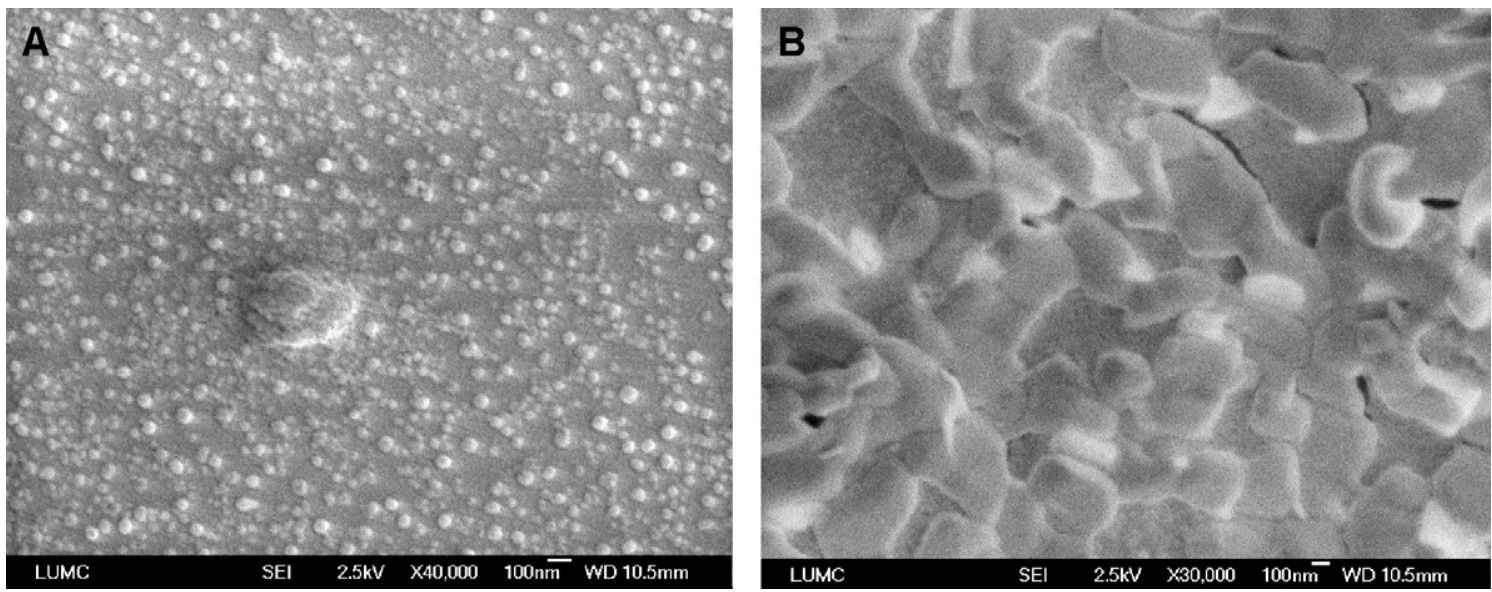

Fig. 1 - Scanning electron micrographs of chitosan nanoparticles: (A) after freeze-dry and re-suspending in water and (B) after the coating with sodium alginate.

layer was confirmed both by FTIR and DSC studies and by the observation of the inversion of the zeta potential to $-34 \mathrm{mV}$.

Ovalbumin release studies from coated and uncoated chitosan nanoparticles, performed with several $\mathrm{pH}$ buffers, allowed us to conclude that the coating with sodium alginate of the ovalbumin loaded chitosan nanoparticles avoided an ovalbumin burst release observed in the first $30 \mathrm{~min}$ compared to uncoated chitosan nanoparticles at pH 5.5; 6.8 and 7.4 (phosphate buffer) (Borges et al., 2006). However at pH 1.2, a burst release was observed for both coated and uncoated nanoparticles. For this reason in the present study a 7\% sodium bicarbonate solution was administered immediately before feeding the mice with the nanoparticles with the purpose to increase the $\mathrm{pH}$ of the stomach fluids.

\section{2. $C p G$ ODN and hepatitis B antigen entrapment in coated nanoparticles}

Different ratios of hepatitis B vaccine to chitosan nanoparticles and CPG ODN to chitosan nanoparticles were investigated (data not shown) and the systems with the highest loading efficacy were used for the further studies. It could be shown that hepatitis B antigen and CPG ODN were efficiently associated with alginate coated chitosan nanoparticles. The loading efficacy of hepatitis B vaccine in the coated nanoparticles was $85.9 \pm 4.7 \%$ (mean \pm S.D.) and the mean of the loading capacity was $25.7 \mu \mathrm{g} \mathrm{HBsAg/mg}$ of dry chitosan nanoparticles \pm 1.42 (S.D.). The loading efficacy of CpG was even better, $98.8 \pm 1.29 \%$ and the loading capacity $29.85 \pm 0.0364$ ( $\mu$ g CpG ODN/mg of dry chitosan nanoparticles) since the existence of a strong interaction between DNA or oligodeoxynucleotides and the oppositely charged cationic chitosan has already been demonstrated (Danielsen et al., 2005; Hillberg and Tabrizian, 2006).

\subsection{Confirmation of the structural integrity of hepatitis $B$ antigen}

The adsorption of hepatitis B antigen (HBsAg) to chitosan nanoparticles occurred at room temperature, under mild agitation using a phosphate buffer as the external medium of the suspension. The coating with alginate was done under similar conditions, being considered as non-aggressive for the entrapment of ODNs, proteins, peptides and vaccines. Nevertheless, a SDS-PAGE analysis followed by a Western blotting was performed in order to confirm the integrity of hepatitis $B$ antigen and the results are shown in Fig. 2 . SDS-PAGE analysis of the bulk vaccine showed the presence of a dominant band with a molecular weight below $30 \mathrm{kDa}$ (Fig. 2b, lane 1) that, according to the literature, was identified to be the $24 \mathrm{kDa}$ polypeptide described by Stephenne (1990) and a second protein with a molecular weight between 35 and $55 \mathrm{kDa}$. The same gel revealed identical bands for the entrapped HBsAg (lanes 2-4) and there were no additional bands to indicate the presence of fragments. Therefore the integrity of the antigen was not affected by the entrapment procedure. Moreover the Western blot membrane shown in Fig. 2a demonstrated that the HBs-specific antibodies from a serum of a vaccinated mouse recognized the antigen epitopes (Fig. 2a, lanes 3-5) in a similar way as for the bulk vaccine (Fig. 2a, lanes 1 and 2), confirming that the antigenicity of the hepatitis $B$ antigen was not altered after the entrapment into nanoparticles.

\subsection{Evaluation of cellular immune responses}

\subsubsection{Lymphoproliferative response}

The cellular immune response of individual mice was evaluated measuring in vitro proliferation of splenocytes, incubated in the presence of HBsAg or in the presence of HBsAg plus $\mathrm{CpG}$ or in the presence of Con A (positive control), respectively. Cells cultured without mitogens were used as a negative control of the experiment and showed as expected only low counts per minute (cpm) values (data not shown). Similar to the negative control were the results obtained with cells incubated only with the antigen (data not shown). The lymphoproliferation in vitro induced by the mixture of the hepatitis B antigen and the immunopotentiator CpG ODN were evaluated in all the groups and are shown in Fig. 3A. The cellular proliferation observed in all the groups was probably caused by the presence of $\mathrm{CpG}$, since it was previously demonstrated that the HBsAg alone in the concentration used did not induce any proliferative effect. 


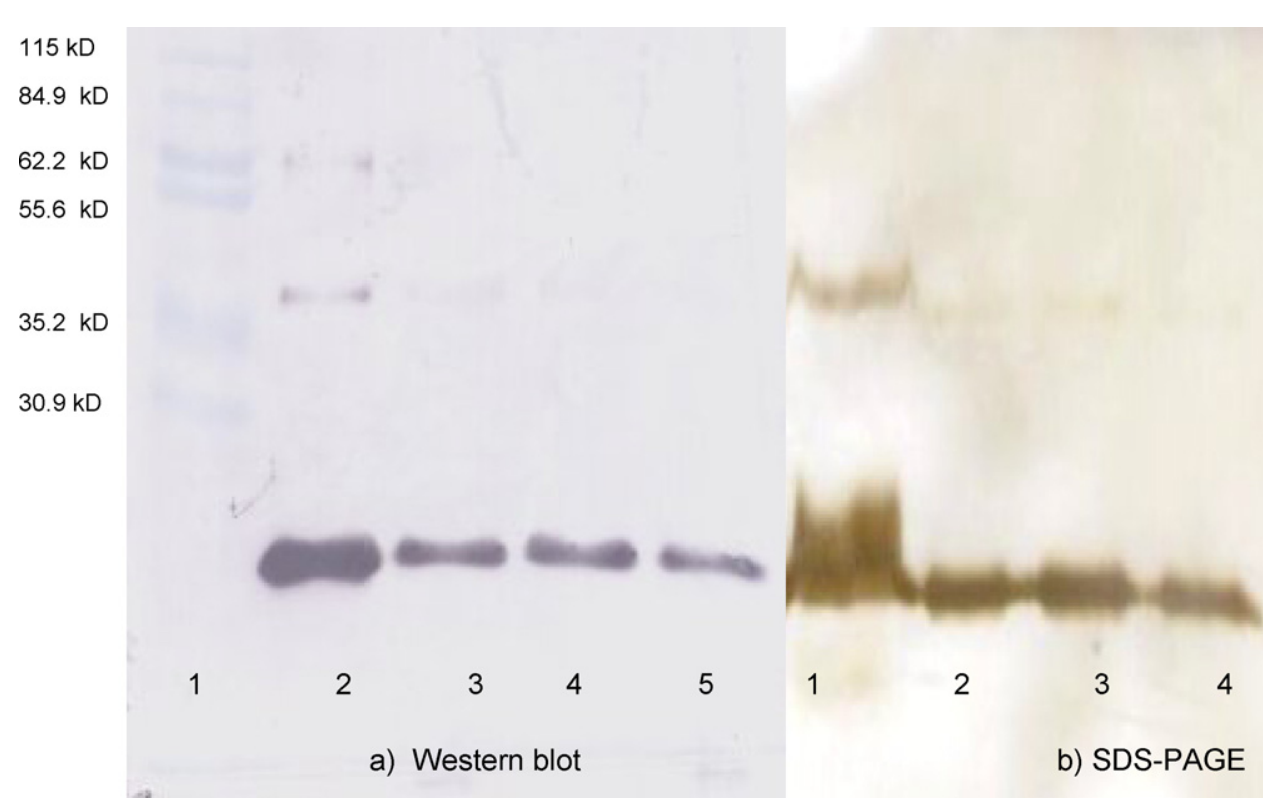

Fig. 2 - Western blot and SDS-PAGE analysis of the released hepatitis B antigen from alginate-coated chitosan nanoparticles. (a) Western blot-lane 1: molecular weight markers; lane 2: HBsAg before association with particles in PBS; lanes 3-5: HBsAg after association with coated nanoparticles and subsequently released overnight in $\mathrm{PBS}$ at $37^{\circ} \mathrm{C}$. (b) SDS-PAGE silver stained-lane 1: HBsAg before association with the particles; lanes 2-4: HBsAg after association with coated nanoparticles and subsequently released overnight in PBS at $37^{\circ} \mathrm{C}$.

The same Fig. 3A showed that the group I (HBsAg associated with nanoparticles) and group VI (HBsAg and CpG associated with nanoparticles) presented a lower splenocyte proliferative capability when compared with the control group. Nevertheless, due to the large variability of the results, the values are not statistically different from the control group. Even less or no proliferation was observed in group IV (HBsAg in solution) and group V (HBsAg and CpG in solution).

Finally, Fig. 3B shows the lymphoproliferative results observed in the presence Con A, a classical mitogen, which served as a positive recall antigen. The groups II, IV and V presented cpm values between 20,000 and 60,000, similar to the control group (group III). These results contrasted with those found for the groups I and VI, where a much stronger proliferative response was observed, showing values between 100,000 and $180,000 \mathrm{cpm}$.

\subsubsection{Cell populations}

The evaluation of spleen cell populations was done immediately after sacrificing the mice. Each individual value and the means for each group are shown in Fig. 4 . The percentage of CD4+ T lymphocytes showed to be similar in all groups. On the other hand, slight but statistically differences were found in the CD8+ T-lymphocyte populations in some treated groups when compared with the control group. In particularly the percentage of CD8+ T-lymphocytes appeared slightly increased in groups IV and V and decreased in groups I and VI.

The increase of the CD8+ T lymphocytes with the decrease of the CD4+/CD8+ ratio as well as a significant decrease of the lymphocyte proliferative response to antigen stimulation, appear to be correlated with the immunological tolerance phenomena (Fanta et al., 1999). The groups IV and V, where antigen or the antigen plus the adjuvant were given in solution, were shown to fulfil these two conditions. On the other hand the association of the antigen with nanoparticles (groups I, II and VI) may have circumvented this undesirable mechanism. Additional studies have to be performed to test this hypothesis.

\subsubsection{Cytokines production}

IL-2 and IFN- $\gamma$ were assayed in the supernatants from splenocytes cultured in the presence of different mitogens (HBsAg, Con $\mathrm{A}$ and the mixture of HBsAg $+\mathrm{CpG}$ ODN) and the results are shown in Fig. 5 . The highest IL-2 mean levels were found in groups I and VI. Nevertheless these results are not statistically significant due to the high variability within the groups. The production of IFN- $\gamma$ by the splenocytes was detected in all the groups in the presence of different mitogens. However the highest mean value was detected in the group VI, where CpG and the antigen were administered associated to the coated nanoparticles, with CPG ODN as the main responsible factor for the high IFN- $\gamma$ production. Therefore, the formulation given to the group VI seemed to be the most effective in the generation of a Th1 profile of immune response.

\subsubsection{Expression of the early activation marker CD69}

CD69 is a type II membrane protein expressed as a homodimer of heavily glycosylated subunits. Both $\mathrm{T}$ and $\mathrm{B}$ cells begin to express CD69 within a few hours after stimulation, being recognized as an early activation marker antigen of lymphocytes. In the present study the expression of CD69 in splenocytes of individual mice was evaluated after $20 \mathrm{~h}$ incubation with different mitogens, being the assay with Con $\mathrm{A}$ as the positive control of the experiment (Fig. 6D). 


\section{Lymphoproliferation assay $(\mathrm{HBsAg}+\mathrm{CpG}$ ODN)}

(A)

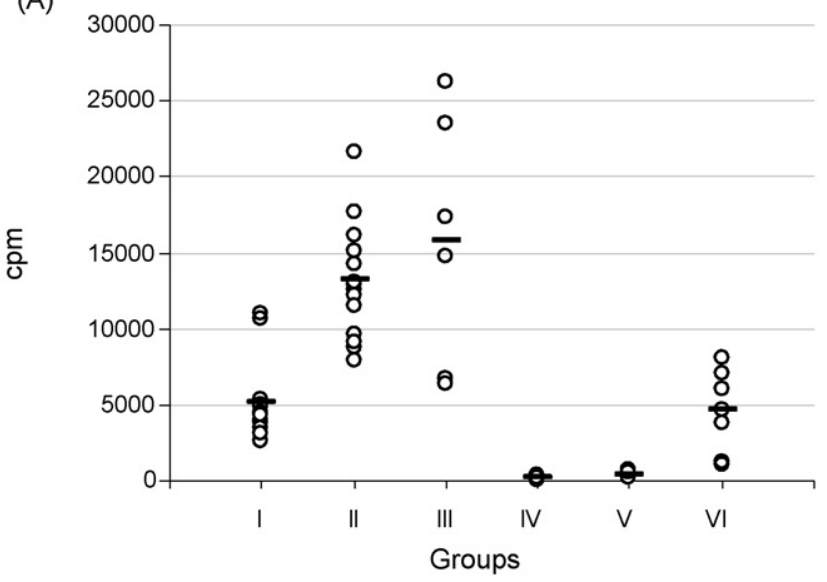

Lymphoproliferation assays

$(\operatorname{con} \mathrm{A})$

(B)

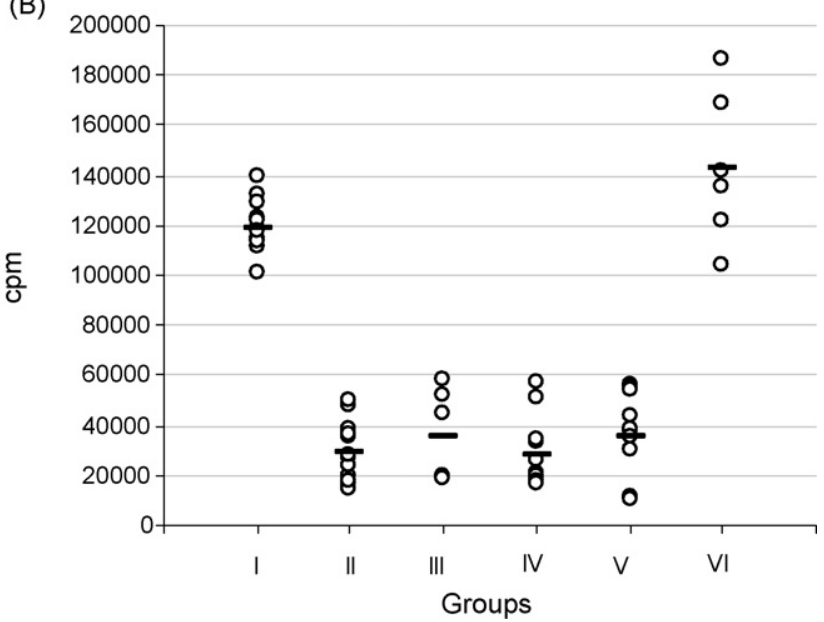

Fig. 3 - Lymphoproliferative response after oral administration of the different hepatitis $B$ vaccine formulations. In vitro proliferation of individual mouse spleenocytes during a $96 \mathrm{~h}$ period stimulated with: $(\mathrm{A})$ HBsAg + CpG ODN; (B) Con A. Each circle represents the result of individual samples and the horizontal bar the mean of the group. The results corresponded to thymidine incorporation and are expressed as counts per minute (cpm).

Cells from the spleen without in vitro stimulation, normally exhibit low levels of CD69 expression as demonstrated in Fig. 6A. In spite of that, significant differences in the CD69 expression on CD4+ T lymphocytes between group I $(p<0.01)$ or group VI $(p<0.01)$ and the control group were observed. The splenocytes were collected 10 days after the boost and cultured for $20 \mathrm{~h}$ without stimulation, which is considered as a long period between the antigen exposure and the CD69 expression. These significant higher values were also observed with HBsAg (Fig. 6B) and HBsAg + CpG (Fig. 6C) in vitro stimulated splenocytes. Despite of the lower CD69 expression levels

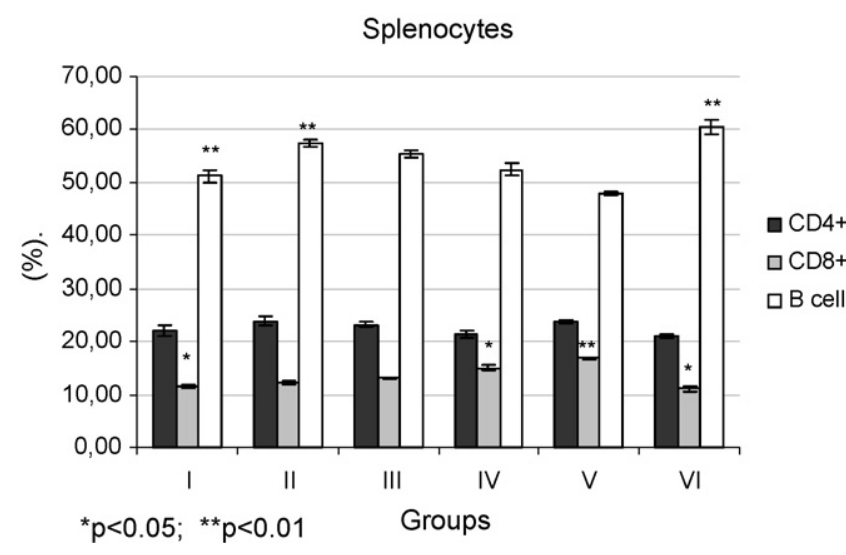

Fig. 4 - Percentage of T-lymphocytes CD4+, CD8+ and B+ lymphocytes in the spleens of mice from the treatment groups (I, II, IV-VI) and the control (naïve mice) group (III) determined by FACS analysis. Each bar corresponds to the group geometric mean plus the standard error of the mean ( $n$ between 3 and 6). The comparison between the control group (III) and the different treatment groups (I, II, IV-VI) was made with a one-way analysis of variance (ANOVA) followed by Dunnett's multiple comparison test $\left({ }^{* *} p<0.01\right.$ and $\left.{ }^{*} p<0.05\right)$.

observed on cells (without in vitro stimulation the values were around $5 \%$ and $13-18 \%$ ) the concordance of the three assays (Fig. 6A-C) gave consistency to the results observed for the groups I and VI. Moreover, in the same groups lower percentages of B lymphocytes CD69+ (8.4 and 7.1\% for the groups I and VI, respectively) were observed when compared with the control group (17\%) (Fig. 6A and B). This result correlates well with the above described lymphoproliferative assay (see Section 3.4.1), where the B lymphocytes showed lower capability to proliferate.

Finally, in the same in vitro study it was observed that the CD8+ T-lymphocytes from the groups I and VI, incubated in the presence of the HBsAg and CpG ODN, expressed significant higher percentage of CD69 molecule $(9.7 \%$ and $12.9 \%$ for the groups I and VI, respectively) when compared with the control group (3.6\%).

\subsection{Humoral immune response}

\subsubsection{Systemic antibody response}

Serum from the mice was collected before the first immunization and before and after the boost and analysed for the anti-HBsAg IgG. The results are shown in Fig. 7 . With only one boost, two of three groups orally vaccinated with the antigen associated with coated nanoparticles were able to show seroconversion. In fact, the group I vaccinated with the HBsAg associated with coated nanoparticles showed a very low responder number (1/6) whereas the group VI, with the antigen and the adjuvant associated with the nanoparticles showed a better result (2/5). This last result was most probably related with the presence of the also encapsulated adjuvant.

IgG subclass titres were measured in responder mice before and after the boost (data not shown). Oral immunization with 

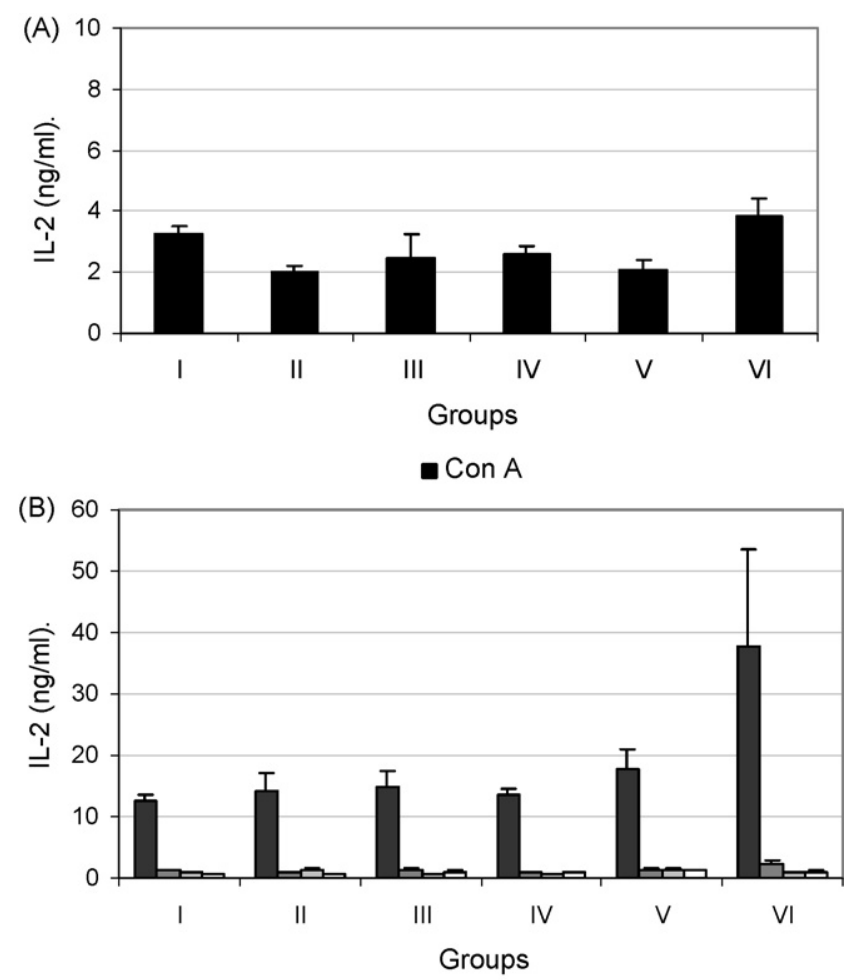

$\square$ Con $\mathrm{A} \quad \mathrm{HBsAg}+\mathrm{CpG} \quad \mathrm{HBsAg}$ a without mitogen

Fig. 5 - Cytoquine production by splenocytes of individual mice from each treatment group: (A) IL-2 secretion from splenocytes cultured for $24 \mathrm{~h}$ in presence of Con A; (B) IFN- $\gamma$ secretion from splenocytes cultured for $86 \mathrm{~h}$ in the absence or in the presence of different mitogens (HBsAg; Con A; HBsAg + CpG ODN). Each bar corresponds to the group geometric mean plus the standard error of the mean ( $n$ between 3 and 6). The comparison between control group (III) and the different treatment groups (I, II, IV-VI) was made using a one-way analysis of variance (ANOVA) followed by Dunnett's multiple comparison test $\left({ }^{* *} p<0.01\right.$ and $\left.{ }^{*} p<0.05\right)$.

HBsAg loaded nanoparticles (group I) induced a Th2 humoral immune response profile (Ig1 $>\operatorname{Ig} 2 a+\operatorname{Ig} 2 b)$, however after the boost, the titres of Ig2a + Ig2b (Th1) were stronger, nevertheless lower than Ig1 (Th2). This mixed Th1/Th2 profile of response has been attributed to the HBsAg on its own (Weeratna et al., 2000). On the other side, the oral immunization with the antigen plus the adjuvant-loaded nanoparticles (group VI) induced a Th1 profile humoral immune response, attributed to the presence of the CpG ODN (Weeratna et al., 2001). This kind of immune response, normally associated with a strong immune cell response, has been claimed for the control of intracellular infections. This includes viral infections, similar to infections with the hepatitis B virus (Rehermann and Nascimbeni, 2005).

\subsubsection{Mucosal anti-HBsAg sIgA}

The results of the determination of the IgA in gut washes are shown in Fig. 8 . These results are presented as ratio between the amount of the specific IgA and the total IgA present in the washes of the gut of each mouse. No significant anti-HBsAg
Without mitogen
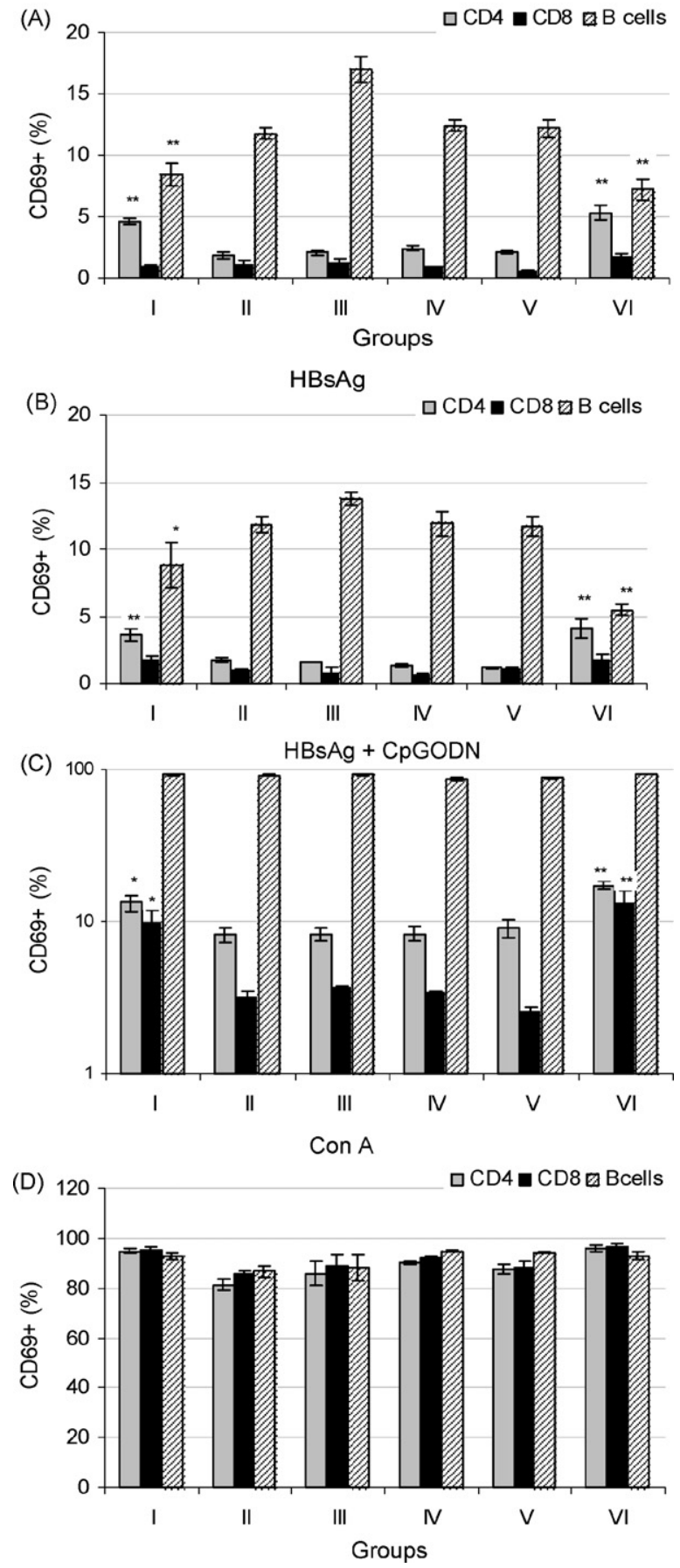

Fig. 6 - Expression of the CD69 antigen on B and T splenocytes from different mouse groups in response to different in vitro stimulation. The stimulus experienced were the immunostimulators, CpGODN (histogram C) and Con A (positive control; histogram D), the antigen, HBsAg (histograms B and C) or without in vitro stimuli (histogram A). The values are mean \pm S.E.M. of the percentage of the positive CD4 cells that express the CD69 antigen, obtained from individual mice of each group ( $n$ between 3 and 6). The comparison between control group (III) and the different treatment groups (I, II, IV-VI) was made with the one-way analysis of variance (ANOVA) with Dunnett's multiple comparison test $\left({ }^{* *} p<0.01\right.$ and $\left.{ }^{*} p<0.05\right)$. 


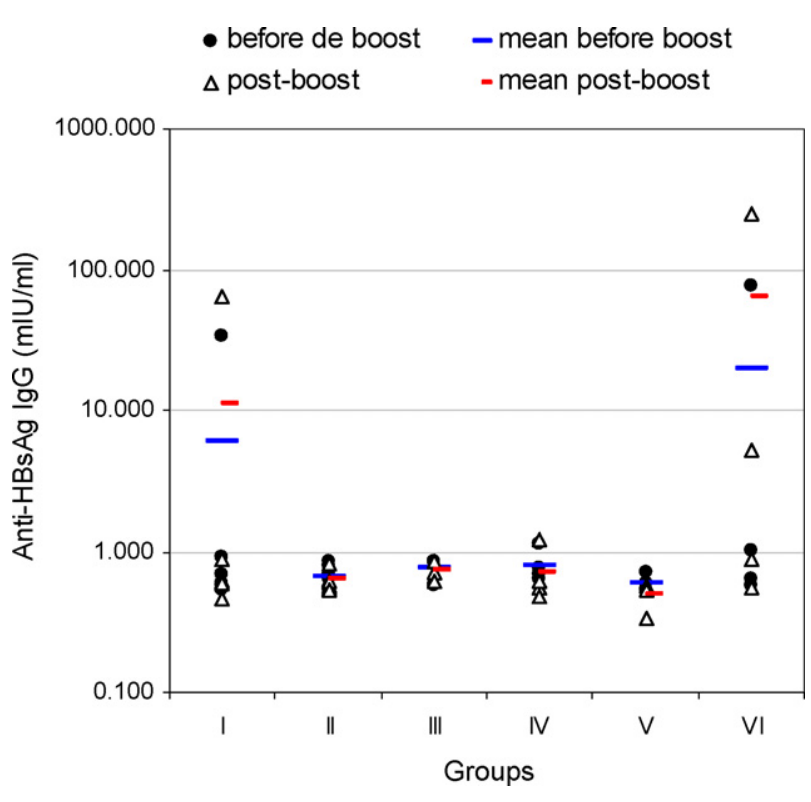

Fig. 7 - Serum anti-HBsAg IgG titres of mice immunized with different oral formulations of hepatitis $B$ vaccine. Values are expressed as antibody titres of individual mice taken before the boost and after the boost. Titres were defined as the highest plasma dilution resulting in an absorbance value twice that of non-immune plasma ( $1 \mathrm{ml} \mathrm{U} / \mathrm{ml}=$ mean +2 S.D. of the control group).

Intestinal washings

o individual values - mean value

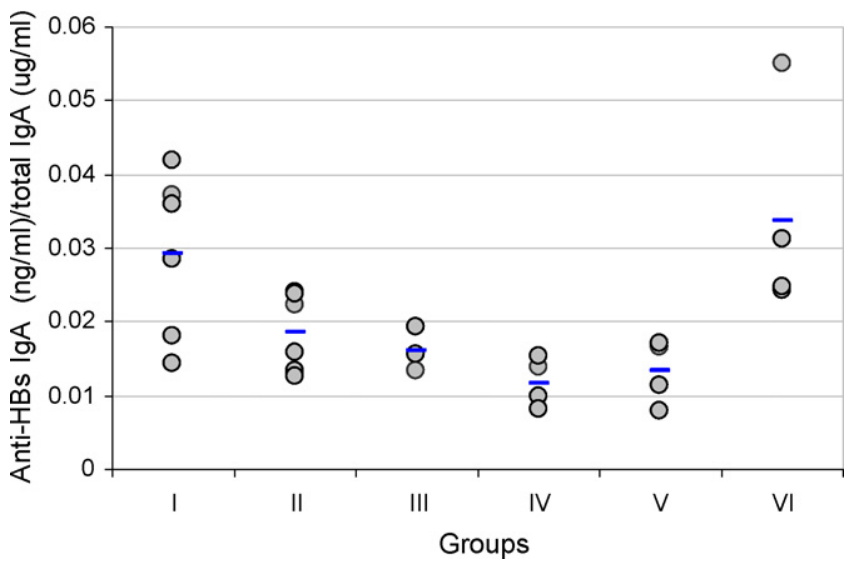

Fig. 8 - Secretory anti-HBsAg sIgA profile detected in individual intestine washing samples of mice immunized with different hepatitis B vaccine oral formulations. Each circle represents the result of individual samples and the horizontal bar the mean of the group. Samples with the value equivalent to mean plus twice the S.D. of the control group (group III), were considered anti-HBsAg sIgA positive. The values were expressed as the ratio between the anti-HBsAg sIgA (ng/ml) and total sIgA ( $\mu \mathrm{g} / \mathrm{ml})$.
IgA was detected in the gut of mice immunized with the solutions of the antigen (groups IV and V). In contrast, detectable anti-HBsAg IgA was quantified in gut washes of some mice from groups I and VI (Fig. 8).

\section{Discussion}

It has been suggested that the response to orally administered antigens is initiated locally in the gut and then disseminated to the secondary lymph nodes and spleen, while other groups suggest a simultaneous activation of antigen-specific $\mathrm{T}$ cells throughout the animal after feeding the antigen (Smith et al., 2002). Following these thoughts, it was investigated if a short time oral vaccination scheme with different formulations of hepatitis B antigen was able to induce not only mucosal but also a systemic (cellular and humoral) immune response. One of the parameters studied was the CD69 expression on the $B$ and $\mathrm{T}$ lymphocytes from the spleen. CD69 is a cell membrane receptor and has not been very often used in vaccination experiments. On the other hand, in a short time study, where an extended immune response is not expected, the investigation of an early activation marker may be useful to quickly evaluate different antigen formulations.

In the present study, the administration of the hepatitis $B$ vaccine entrapped in alginate-coated chitosan nanoparticles was investigated. In some cases (groups I and VI), those formulations were able to induce a cellular immune response, translated by the highest percentage of CD4+ T-lymphocytes expressing the CD69 and the lowest percentage of CD69+ B cells. Moreover, in the same groups, the CD8+ T-lymphocytes have shown to be the most susceptible to CD69 induction when cultured in the presence of the antigen plus the adjuvant. Furthermore, the lymphocytes from those groups (I and VI) also have shown the highest capacity to proliferate and in some cases to produce IL- 2 and IFN- $\gamma$. This cellular immune response was accompanied by the presence of IgG and IgA HBsAg specific in the serum and on the intestinal mucosa, respectively, however with the presence of non-responder mice within the groups (I and VI). In the recent literature (McCluskie et al., 2000a,b), the presence of non-responder orally or even nasally vaccinated mice is frequently reported, especially when the evaluation of the specific antibodies was performed after a single immunization. Moreover, to have a high percentage of seroconverted mice within the groups orally vaccinated, it has been always necessary to administer higher antigen concentrations with successive administration of the vaccine. Commercial injectable hepatitis $B$ vaccines also have this drawback in humans (Rendi-Wagner et al., 2006). It was estimated that the priming doses only induce detectable levels of antibodies in 70-90\% of healthy infants, adolescents and adults. The final boost of the vaccine induces protective levels of anti-HBs antibodies in more than 95\% (Rendi-Wagner et al., 2006) of infants and adolescents. In our study, the vaccination with a solution with $10 \mu \mathrm{g}$ of the antigen (groups IV and V) did not induce cellular or humoral immune response and the results shown in this work allowed us to hypothesize that immunological tolerance might have been induced. In fact, oral tolerance has been one of the principal obstacles to different strategies designed for the oral administration 
of the vaccines and its induction seems to be related with the antigen dose (Gotsman et al., 2000; Pecquet et al., 2000) and also most probably with the intrinsic properties of the antigen. Identical to our results obtained with a solution of the antigen were found in literature (McCluskie and Davis, 2000). Even when the dose was increased to $100 \mu \mathrm{g}$, the vaccine given orally did not induce at all or in some cases only low anti-HBsAg IgG titers (McCluskie et al., 2000b). However, the association of CpG ODN (McCluskie et al., 2000b) or of PLG microparticles (Rajkannan et al., 2006) to the same high dose of the vaccine-induced a systemic and mucosal immune response.

In order to obtain an immune response, the increase of the antigen dose used may not be sufficient to produce immunological acceptable results. Moreover, those high concentrations may not be economically attractive and hence different solutions have to be explored. The development of efficient adjuvants for the mucosal route is one of the more promising approaches. One of the examples was recently described in the literature, the CpG ODN. A number of studies have shown that the CpG ODN is an effective immunomodulator molecule for parenteral (McCluskie et al., 2001a; Weeratna et al., 2001) and mucosal routes (McCluskie et al., 2000a,b, 2001b,c). Moreover, CpG ODN has been shown to induce Th1 profile immune responses with a number of different antigens (Diwan et al., 2002; Weeratna et al., 2001).

In the present study, the profile of the immune response, observed in the group VI, vaccinated with the hepatitis B antigen and the CpG ODN, both associated with nanoparticles, was re-directed to a Th-1 profile, when compared with the Th2 immune response observed in group I (vaccinated just with the antigen associated with the nanoparticles). Additionally, it was observed an increase of the percentage of responder mice when the CpG ODN encapsulated was included in the formulation (group VI). Therefore, this formulation (group VI) may also have a promising potential for the improvement of the currently licensed HBV vaccines, in particular to make them useful also in the treatment of chronic hepatitis B, where is required a strong Th-1 cellular immune response induction. Nevertheless it would be worth examining if the controlled delivery of the antigen and the CPG ODN from the chitosan nanoparticles is also able to enhance the longevity of the immune response.

The mechanism of adjuvant action of CpG ODN is not completely understood, but it is known that CpG ODN binds to the toll-like receptor 9 (TLR-9) (McCluskie and Weeratna, 2006). Therefore the immunostimulator effect is mediated only after its cell internalization (Diwan et al., 2002). On the other hand, the entrapment of CPG into nanoparticles with a size larger than a cell, may fail to stimulate immune cells, most probably because the nanoparticles cannot be internalised.

The physical proximity of the antigen and the adjuvant seems to be a requirement for an effective adjuvant effect (Davis et al., 1998). This hypothesis could be the key, at least in part, of the lack of an early immune response observed in our study with the group of mice treated with the antigen associated with the nanoparticles and the adjuvant in solution (group II). The hepatitis B antigen associated to the nanoparticles and the adjuvant in solution may have been taken up in different regions of the intestine. According to our own previous studies (Borges et al., 2006), alginate-coated chitosan nanoparticles can be taken up by Peyer's patches and the CpG ODN in solution was most probably internalized by the enterocytes. On the contrary in the group VI, antigen and adjuvant, both associated to the nanoparticles, were most probably internalized simultaneously by M-cells of the Peyer's patches and this fact may explain the better results observed in this group.

\section{Conclusion}

Alginate-coated chitosan nanoparticles are able to entrap efficiently the hepatitis B recombinant vaccine and the CpG ODN used as an adjuvant.

Humoral and cellular immune response were better induced in mice vaccinated with the formulation where the antigen and the adjuvant appeared associated with the nanoparticles. The Th1 profile immune response induced by this formulation is crucial in preventing or overcoming hepatitis B infections, thus making this delivery system a promising one. However further studies and in time prolonged with additional boosts have to be done in order to evaluate the appearance of desirable new responder mice. Also it has to be demonstrated whether a long lasting cellular and humoral immune response can be induced with this formulation using this challenging oral administration route.

\section{Acknowledgements}

The authors wish to thank Dr. Martine Wettendorf and Dr. Sandra Giannini (GlaxoSmithKline, Biologicals, Belgium) for providing the hepatitis $B$ vaccine.

\section{REFERENCES}

Babensee, J.E., Paranjpe, A., 2005. Differential levels of dendritic cell maturation on different biomaterials used in combination products. J. Biomed. Mater. Res. A 74, 503-510.

Bacon, A., Makin, J., Sizer, P.J., Jabbal-Gill, I., Hinchcliffe, M., Illum, L., Chatfield, S., Roberts, M., 2000. Carbohydrate biopolymers enhance antibody responses to mucosally delivered vaccine antigens. Infect. Immun. 68, 5764-5770.

Baudner, B.C., Balland, O., Giuliani, M.M., Von Hoegen, P., Rappuoli, R., Betbeder, D., Del Giudice, G., 2002. Enhancement of protective efficacy following intranasal immunization with vaccine plus a nontoxic LTK63 mutant delivered with nanoparticles. Infect. Immun. 70, 4785-4790.

Baudner, B.C., Verhoef, J.C., Giuliani, M.M., Peppoloni, S., Rappuoli, R., Del Giudice, G., Junginger, H.E., 2005. Protective immune responses to meningococcal $C$ conjugate vaccine after intranasal immunization of mice with the LTK63 mutant plus chitosan or trimethyl chitosan chloride as novel delivery platform. J. Drug Target 13, 489-498.

Bloom, B.R., Widdus, R., 1998. Vaccine visions and their global impact. Nat. Med. 4, 480-484.

Borges, O., Borchard, G., Verhoef, J.C., de Sousa, A., Junginger, H.E., 2005. Preparation of coated nanoparticles for a new mucosal vaccine delivery system. Int. J. Pharm. 299, 155-166.

Borges, O., Cordeiro-da-Silva, A., Romeijn, S.G., Amidi, M., de Sousa, A., Borchard, G., Junginger, H.E., 2006. Uptake studies in rat Peyer's patches, cytotoxicity and release studies of alginate 
coated chitosan nanoparticles for mucosal vaccination. J. Control Release 114, 348-358.

Borges, O., Borchard, G., de Sousa, A., Junginger, H.E., Cordeiro-da-Silva, A., 2007. Induction of lymphocytes activated marker CD69 following exposure to chitosan and alginate biopolymers. Int. J. Pharm. 337, 254-264.

Carpentier, A., Laigle-Donadey, F., Zohar, S., Capelle, L., Behin, A., Tibi, A., Martin-Duverneuil, N., Sanson, M., Lacomblez, L., Taillibert, S., Puybasset, L., Van Effenterre, R., Delattre, J.Y., Carpentier, A.F., 2006. Phase 1 trial of a CpG oligodeoxynucleotide for patients with recurrent glioblastoma. Neuro-oncol. 8, 60-66.

Coligan, J.E. (Ed.), 2001. Current Protocols in Immunology. John Wiley \& Sons Inc., New York.

Cooper, C.L., Davis, H.L., Morris, M.L., Efler, S.M., Adhami, M.A., Krieg, A.M., Cameron, D.W., Heathcote, J., 2004. CPG 7909, an immunostimulatory TLR9 agonist oligodeoxynucleotide, as adjuvant to Engerix-B HBV vaccine in healthy adults: a double-blind phase I/II study. J. Clin. Immunol. 24, 693-701.

Cordeiro-da-Silva, A., Tavares, J., Araujo, N., Cerqueira, F., Tomas, A., Kong Thoo Lin, P., Ouaissi, A., 2004. Immunological alterations induced by polyamine derivatives on murine splenocytes and human mononuclear cells. Int. Immunopharmacol. 4, 547-556.

Danielsen, S., Maurstad, G., Stokke, B.T., 2005. DNA-polycation complexation and polyplex stability in the presence of competing polyanions. Biopolymers 77, 86-97.

Davis, H.L., Weeratna, R., Waldschmidt, T.J., Tygrett, L., Schorr, J., Krieg, A.M., 1998. CpG DNA is a potent enhancer of specific immunity in mice immunized with recombinant hepatitis $B$ surface antigen. J. Immunol. 160, 870-876.

Diwan, M., Tafaghodi, M., Samuel, J., 2002. Enhancement of immune responses by co-delivery of a CpG oligodeoxynucleotide and tetanus toxoid in biodegradable nanospheres. J. Control Release 85, 247-262.

Fanta, C., Bohle, B., Hirt, W., Siemann, U., Horak, F., Kraft, D., Ebner, H., Ebner, C., 1999. Systemic immunological changes induced by administration of grass pollen allergens via the oral mucosa during sublingual immunotherapy. Int. Arch. Allergy Immunol. 120, 218-224.

Friedberg, J.W., Kim, H., McCauley, M., Hessel, E.M., Sims, P., Fisher, D.C., Nadler, L.M., Coffman, R.L., Freedman, A.S., 2005. Combination immunotherapy with a CpG oligonucleotide (1018 ISS) and rituximab in patients with non-Hodgkin lymphoma: increased interferon-alpha/beta-inducible gene expression, without significant toxicity. Blood 105, 489-495.

Gao, Y., Ma, Y., Li, M., Cheng, T., Li, S.W., Zhang, J., Xia, N.S., 2003. Oral immunization of animals with transgenic cherry tomatillo expressing HBsAg. World J. Gastroenterol. 9, 996-1002.

Gotsman, I., Beinart, R., Alper, R., Rabbani, E., Engelhardt, D., Ilan, Y., 2000. Induction of oral tolerance towards hepatitis $B$ envelope antigens in a murine model. Antiviral Res. 48, 17-26.

He, X.W., Wang, F., Jiang, L., Li, J., Liu, S.K., Xiao, Z.Y., Jin, X.Q., Zhang, Y.N., He, Y., Li, K., Guo, Y.J., Sun, S.H., 2005. Induction of mucosal and systemic immune response by single-dose oral immunization with biodegradable microparticles containing DNA encoding HBsAg. J. Gen. Virol. 86, 601-610.

Hillberg, A.L., Tabrizian, M., 2006. Biorecognition through layer-by-layer polyelectrolyte assembly: in situ hybridization on living cells. Biomacromolecules 7, 2742-2750.

Holmgren, J., Czerkinsky, C., 2005. Mucosal immunity and vaccines. Nat. Med. 11, S45-S53.

Jaganathan, K.S., Vyas, S.P., 2006. Strong systemic and mucosal immune responses to surface-modified PLGA microspheres containing recombinant hepatitis B antigen administered intranasally. Vaccine 24, 4201-4211.

Jaganathan, K.S., Rao, Y.U., Singh, P., Prabakaran, D., Gupta, S., Jain, A., Vyas, S.P., 2005. Development of a single dose tetanus toxoid formulation based on polymeric microspheres: a comparative study of poly(D,L-lactic-co-glycolic acid) versus chitosan microspheres. Int. J. Pharm. 294, 23-32.

Kapusta, J., Modelska, A., Figlerowicz, M., Pniewski, T., Letellier, M., Lisowa, O., Yusibov, V., Koprowski, H., Plucienniczak, A., Legocki, A.B., 1999. A plant-derived edible vaccine against hepatitis B virus. FASEB J. 13, 1796-1799.

Kapusta, J., Modelska, A., Pniewski, T., Figlerowicz, M., Jankowski, K., Lisowa, O., Plucienniczak, A., Koprowski, H., Legocki, A.B., 2001. Oral immunization of human with transgenic lettuce expressing hepatitis B surface antigen. Adv. Exp. Med. Biol. 495, 299-303.

Klinman, D.M., Currie, D., Gursel, I., Verthelyi, D., 2004. Use of CpG oligodeoxynucleotides as immune adjuvants. Immunol. Rev. 199, 201-216.

Kong, Q., Richter, L., Yang, Y.F., Arntzen, C.J., Mason, H.S., Thanavala, Y., 2001. Oral immunization with hepatitis B surface antigen expressed in transgenic plants. Proc. Natl. Acad. Sci. U.S.A. 98, 11539-11544.

McCluskie, M.J., Davis, H.L., 2000. Oral, intrarectal and intranasal immunizations using $\mathrm{CpG}$ and non-CpG oligodeoxynucleotides as adjuvants. Vaccine 19, 413-422.

McCluskie, M.J., Weeratna, R.D., 2006. CpG oligodeoxynucleotides as vaccine adjuvants. In: Schijins, V., O'Hagan, D. (Eds.), Immunopotentiators in Modern Vaccines. Academic Press, pp. 73-92.

McCluskie, M.J., Weeratna, R.D., Davis, H.L., 2000a. Intranasal immunization of mice with CPG DNA induces strong systemic and mucosal responses that are influenced by other mucosal adjuvants and antigen distribution. Mol. Med. 6, 867-877.

McCluskie, M.J., Weeratna, R.D., Krieg, A.M., Davis, H.L., $2000 \mathrm{~b}$. CpG DNA is an effective oral adjuvant to protein antigens in mice. Vaccine 19, 950-957.

McCluskie, M.J., Weeratna, R.D., Davis, H.L., 2001a. The potential of oligodeoxynucleotides as mucosal and parenteral adjuvants. Vaccine 19, 2657-2660.

McCluskie, M.J., Weeratna, R.D., Payette, P.J., Davis, H.L., $2001 b$. The potential of CpG oligodeoxynucleotides as mucosal adjuvants. Crit. Rev. Immunol. 21, 103-120.

McCluskie, M.J., Weeratna, R.D., Payette, P.J., Davis, H.L., 2001c. The use of CpG DNA as a mucosal vaccine adjuvant. Curr. Opin. Invest. Drugs 2, 35-39.

Mowat, A.M., 2003. Anatomical basis of tolerance and immunity to intestinal antigens. Nat. Rev. Immunol. 3, 331-341.

Nagler-Anderson, C., 2001. Man the barrier! Strategic defences in the intestinal mucosa. Nat. Rev. Immunol. 1, 59-67.

Neutra, M.R., Kozlowski, P.A., 2006. Mucosal vaccines: the promise and the challenge. Nat. Rev. Immunol. 6, 148-158.

Nishimura, K., Nishimura, S., Seo, H., Nishi, N., Tokura, S., Azuma, I., 1987. Effect of multiporous microspheres derived from chitin and partially deacetylated chitin on the activation of mouse peritoneal macrophages. Vaccine 5, 136-140.

Osorio, J.E., Zuleger, C.L., Burger, M., Chu, Q., Payne, L.G., Chen, D., 2003. Immune responses to hepatitis $B$ surface antigen following epidermal powder immunization. Immunol. Cell Biol. 81, 52-58.

Pecquet, S., Leo, E., Fritsche, R., Pfeifer, A., Couvreur, P., Fattal, E., 2000. Oral tolerance elicited in mice by beta-lactoglobulin entrapped in biodegradable microspheres. Vaccine 18 , 1196-1202.

Rajkannan, R., Dhanaraju, M.D., Gopinath, D., Selvaraj, D., Jayakumar, R., 2006. Development of hepatitis B oral vaccine using B-cell epitope loaded PLG microparticles. Vaccine 24, 5149-5157.

Read, R.C., Naylor, S.C., Potter, C.W., Bond, J., Jabbal-Gill, I., Fisher, A., Illum, L., Jennings, R., 2005. Effective nasal influenza vaccine delivery using chitosan. Vaccine 23, 4367-4374. 
Rehermann, B., Nascimbeni, M., 2005. Immunology of hepatitis B virus and hepatitis $C$ virus infection. Nat. Rev. Immunol. 5, 215-229.

Rendi-Wagner, P., Shouval, D., Genton, B., Lurie, Y., Rumke, H., Boland, G., Cerny, A., Heim, M., Bach, D., Schroeder, M., Kollaritsch, H., 2006. Comparative immunogenicity of a PreS/S hepatitis $\mathrm{B}$ vaccine in non- and low-responders to conventional vaccine. Vaccine 24, 2781-2789.

Shibata, Y., Foster, L.A., Metzger, W.J., Myrvik, Q.N., 1997. Alveolar macrophage priming by intravenous administration of chitin particles, polymers of $\mathrm{N}$-acetyl-D-glucosamine, in mice. Infect. Immunol. 65, 1734-1741.

Smith, K.M., Davidson, J.M., Garside, P., 2002. T-cell activation occurs simultaneously in local and peripheral lymphoid tissue following oral administration of a range of doses of immunogenic or tolerogenic antigen although tolerized $\mathrm{T}$ cells display a defect in cell division. Immunology 106, 144-158.

Stephenne, J., 1990. Development and production aspects of a recombinant yeast-derived hepatitis B vaccine. Vaccine 8 (Suppl.), S69-S73, discussion S79-80.

Thanavala, Y., Mahoney, M., Pal, S., Scott, A., Richter, L., Natarajan, N., Goodwin, P., Arntzen, C.J., Mason, H.S., 2005. Immunogenicity in humans of an edible vaccine for hepatitis B. Proc. Natl. Acad. Sci. U.S.A. 102, 3378-3382.

van der Lubben, I.M., Kersten, G., Fretz, M.M., Beuvery, C., Coos Verhoef, J., Junginger, H.E., 2003. Chitosan microparticles for mucosal vaccination against diphtheria: oral and nasal efficacy studies in mice. Vaccine 21, 1400-1408.
Vila, A., Sanchez, A., Janes, K., Behrens, I., Kissel, T., Vila Jato, J.L., Alonso, M.J., 2004. Low molecular weight chitosan nanoparticles as new carriers for nasal vaccine delivery in mice. Eur. J. Pharm. Biopharm. 57, 123-131.

Weeratna, R.D., McCluskie, M.J., Xu, Y., Davis, H.L., 2000. CpG DNA induces stronger immune responses with less toxicity than other adjuvants. Vaccine 18, 1755-1762.

Weeratna, R.D., Brazolot Millan, C.L., McCluskie, M.J., Davis, H.L., 2001. CpG ODN can re-direct the Th bias of established Th2 immune responses in adult and young mice. FEMS Immunol. Med. Microbiol. 32, 65-71.

WHO, 2005. Vaccine-Preventable Diseases: Monitoring System 2005 Global Summary. Department of Immunization, Vaccines and Biologicals. World Health Organization, Geneva, Switzerland.

Woo, P.C., Wong, L.P., Zheng, B.J., Yuen, K.Y., 2001. Unique immunogenicity of hepatitis B virus DNA vaccine presented by live-attenuated Salmonella typhimurium. Vaccine 19, 2945-2954.

Zheng, B., Woo, P.C., Ng, M., Tsoi, H., Wong, L., Yuen, K., 2001. A crucial role of macrophages in the immune responses to oral DNA vaccination against hepatitis $B$ virus in a murine model. Vaccine 20, 140-147.

Zheng, B.J., Ng, M.H., Chan, K.W., Tam, S., Woo, P.C., Ng, S.P., Yuen, K.Y., 2002. A single dose of oral DNA immunization delivered by attenuated Salmonella typhimurium down-regulates transgene expression in HBsAg transgenic mice. Eur. J. Immunol. 32, 3294-3304. 